Short communication

\title{
Acceptability of audio computer-assisted self-interview (ACASI) among substance abusers seeking treatment in Rio de Janeiro, Brazil
}

\author{
Anna Azevedo Simões ${ }^{\mathrm{a}, *}$, Francisco Inacio Bastos ${ }^{\mathrm{b}}$, \\ Ronaldo Ismerio Moreira ${ }^{b}$, Kevin G. Lynch ${ }^{\mathrm{c}}$, David S. Metzger ${ }^{\mathrm{c}}$ \\ ${ }^{a}$ Health Department of the State Government of Rio de Janeiro, Brazil \\ ${ }^{b}$ Oswaldo Cruz Foundation, Rio de Janeiro, Brazil \\ ${ }^{\circ}$ University of Pennsylvania, Philadelphia, PA, USA
}

Received 1 May 2005; received in revised form 10 August 2005; accepted 13 October 2005

\begin{abstract}
This study aimed to determine the acceptability of the ACASI approach to risk assessment and the impact of personal preference regarding mode of interview on reporting risk behaviors among drug users entering treatment in Rio de Janeiro, Brazil. We assessed 268 substance users who completed the ACASI arm in a randomized trial comparing the ACASI with the Interviewer-Administered Questionnaire (IAQ). The vast majority of interviewees $(90.7 \%$ ) reported no problem using the computer, and $37.3 \%$ felt that their privacy was best protected by the ACASI (vs. 16.4\% who preferred the IAQ). Nearly half (45.5\%) reported that the computer interview would produce more "honest" answers, whereas $30.6 \%$ selected the IAQ. In the adjusted regression analysis, problems using the computer were associated only with lower educational level $(p<0.05)$. We found no evidence that preference had an impact on reporting risk behaviors or drug use. Our study showed both good feasibility and acceptability of the ACASI for interviewing drug users in Brazil. The findings extend our understanding of the role of the ACASI method by suggesting the utility of this approach in assessing HIV risk among low- to middle-income drug users in a cultural setting quite different from previous studies.

(C) 2006 Elsevier Ireland Ltd. All rights reserved.
\end{abstract}

Keywords: Acceptability; ACASI; Substance abuse; Risk behavior; HIV/STI

\section{Introduction}

The collection of data on risk behaviors for the transmission of HIV and other bloodborne and sexually transmitted infections (STIs) continues to be a challenge, especially among drug users. There is substantial evidence that subjects do not fully disclose to interviewers behaviors that can be considered socially embarrassing or illegal, and the need to minimize the bias associated with InterviewerAdministered Questionnaires (IAQs) has led researchers to explore computer-enhanced methods of data collection (Lucas et al., 1977; LoSciuto et al., 1993; Mills et al., 1996; Aquilino, 1997; Des Jarlais et al., 1999; Kissinger et al., 1999; Aquilino et al., 2000; Metzger et al., 2000; Cooley et al., 2001; Ellen et al., 2002). As a result of this research, there is currently widespread support for the use of the Audio Computer-Assisted Self-Interview (ACASI) mode of questionnaire administration.

\footnotetext{
* Corresponding author. Tel.: +55 212299 5920; fax: +55 212299 5922.

E-mail address: annago@uol.com.br (A. Simões).
}

The ACASI mode of data collection allows the respondent to answer questions in the absence of a human interviewer and might help to minimize the extent of missing data for sensitive items and facilitate the consistent implementation of complex skip patterns. Other important advantages include extending its use to individuals with low levels of literacy or with languages that are not familiar to the research staff, and reducing the time and cost associated with data entry using traditional paper-and-pencil questionnaires.

Support for the use of the ACASI method in assessing HIV risk behaviors is propelled by a growing body of research that strongly suggests that ACASI use enhances reports of sensitive and illegal behavior (Millstein, 1987; Locke et al., 1992; Kissinger et al., 1999; Turner et al., 1998; Des Jarlais et al., 1999; Metzger et al., 2000; Gribble et al., 2000; Riley et al., 2001; Newman et al., 2002; Jennings et al., 2002; Mensch et al., 2003; Simões et al., 2006). Although a few studies of the ACASI method have been conducted in developing countries, the global epidemiology of AIDS contributes to the need for more 
research evaluating the use and acceptability of ACASI outside the USA (Simões and Bastos, 2004).

The acceptability of the ACASI method has been reported in a few studies conducted in the USA and in two developing countries. The majority of the participants in these studies reported good acceptance and felt comfortable with the technology (Lucas et al., 1977; Davis and Morse, 1991; Navaline et al., 1994; Kissinger et al., 1999; Van de Wijgert et al., 2000; Metzger et al., 2000; Cooley et al., 2001; Hewet et al., 2004).

Using data from a recently completed randomized trial comparing ACASI with IAQ among a population of drug users seeking treatment in Rio de Janeiro, Brazil, we report on the acceptability of the ACASI mode and the impact of "mode preference" on the ability of the ACASI approach to enhance reports of drug use and risk behaviors.

\section{Method}

\subsection{ACORI project}

The risk assessment behavior project (ACORI) was the first to use and evaluate the ACASI method in Brazil. This randomized trial compared reports of drug use and HIV risk behaviors collected via ACASI and IAQ in an effort to assess the feasibility and acceptability of using the ACASI method in this population (as detailed elsewhere; Simões et al., 2006). The project was carried out in a public health facility dedicated to the management of alcohol and drug problems (Centra Rio/SES). This intensive outpatient program has approximately 1000 admissions annually and serves a socioeconomically diverse population of adults, adolescents, and their families.

The ACORI Project analyzed data from 735 individuals: 367 on the ACASI and 368 on the face-to-face interview. The comparative study used a questionnaire derived from the Risk Assessment Battery (RAB), which assesses recent drug use and risk behavior among drug users. The programming of the Portuguese ACASI version utilized a software product specifically designed for ACASI development. The computer version questions were identical to those that appear on the paper version, and skip patterns were programmed in accordance with the administration instructions. The system was designed so that participants indicated their response to questions using a mouse. The ACASI version presents each question on a separate screen. It was programmed so that the participant could not skip a question without choosing one of the response options. Each screen also provided an option "button" that would allow participants to repeat the question and response choices as many times as needed. The sound files were recorded using a female human voice with a pleasant, professional tone and without a distinct accent. This decision reflects our desire to maximize clarity and our concern about the potential for some respondents to react to distinct accents.

\subsection{Acceptability Questionnaire}

To assess acceptability, subjects were asked to respond to a self-administered questionnaire after completing the ACASI interview. Interviewers administered the questions to participants with limited literacy skills. The acceptability questionnaire contained questions related to problems in using the computer, which mode of interview best protected the privacy of responses, which mode would elicit the most honest answers from others, and which mode subjects would prefer to use in future interviews. Additional comments and suggestions also were elicited from the participants.

\subsection{Statistical analyses}

Descriptive statistics were used to compare the demographic characteristics of respondents and their answers to each question regarding the acceptability of the ACASI mode of administration. Pearson's Chi-square test was used to analyze dichotomous variables. A $p$-value of $<0.05$ was set as statistically significant. Demographic variables associated with the question "Did you have difficulties in managing the computer?" were examined. We calculated adjusted odds ratios (ORs) (and respective 95\% confidence intervals [CIs]) to assess putative associations between reports of risk behaviors and drug use and preference for mode of interview. Adjusted ORs controlled for gender, age, race, level of education, and income. Participants' comments and suggestions were summarized.

\section{Results}

A total of 268 subjects assigned to the ACASI arm of the parent study completed the acceptability questionnaire. Sociodemographic characteristics are displayed in Table 1. The participants' mean age was 36 years $(\mathrm{SD}=10)$; $83.6 \%$ were male; $51.5 \%$ white; $67.2 \%$ had less than a

Table 1

Characteristics of participants who answered the acceptability questionnaire

\begin{tabular}{lrr|lll}
\hline $\begin{array}{l}\text { Sociodemographic } \\
\text { characteristics }\end{array}$ & $n^{\mathrm{a}}$ & $\%$ & $\begin{array}{l}\text { Sociodemographic } \\
\text { characteristics }\end{array}$ & $n^{\mathrm{a}}$ & $\%$ \\
\hline Sex & & & Race & & \\
$\quad$ Male & 224 & 83.6 & White & 138 & 51.5 \\
$\quad$ Female & 44 & 16.4 & Nonwhite & 129 & 48.1 \\
Age & & & Education & & \\
$\quad 18-25$ & 46 & 17.2 & $<$ High school & 180 & 67.2 \\
$26-35$ & 87 & 32.5 & $\geqslant$ High school & 84 & 31.3 \\
$36-45$ & 90 & 33.6 & Income & \\
$46-55$ & 37 & 13.8 & $\leqslant 246 \$$ & 114 & 42.5 \\
$>56$ & 8 & 3.0 & $>246 \$$ & 104 & 38.8 \\
\hline
\end{tabular}

a Total in each category does not add up to 268 because of missing data.

b Average monthly income in the city of Rio de Janeiro in 2000 (CensoIBGE), with Reais (Brazilian currency)/US\$ exchange rate as made available by the Brazilian newspaper Estado de São Paulo (2003). 
Table 2

Sexual risk and drug use among ACASI-assessed subjects by preference for mode of interview

\begin{tabular}{|c|c|c|c|c|c|c|}
\hline Characteristic & ACASI/no preference & IAQ & $\mathrm{OR}^{\mathrm{a}}$ & $95 \% \mathrm{CI}$ & $\mathrm{AOR}^{\mathrm{b}}$ & $95 \% \mathrm{CI}$ \\
\hline \multicolumn{7}{|l|}{ Sexual risk } \\
\hline Sexually active & $152(91.6 \%)$ & $94 \quad(92.2 \%)$ & 0.92 & $0.37-2.29$ & 0.86 & $0.34-2.18$ \\
\hline MSM & $16(11.8 \%)$ & $12(13.6 \%)$ & 0.84 & $0.38-1.88$ & 0.78 & $0.34-1.78$ \\
\hline Sex with HIV+ & $5 \quad(3.0 \%)$ & $3 \quad(2.9 \%)$ & 1.03 & $0.24-4.38$ & 1.28 & $0.29-5.63$ \\
\hline Money for sex & $46(27.7 \%)$ & $23(22.5 \%)$ & 1.31 & $0.74-2.34$ & 1.48 & $0.82-2.71$ \\
\hline Drugs for sex & $33(19.9 \%)$ & $17(16.7 \%)$ & 1.24 & $0.65-2.36$ & 0.40 & $0.68-2.57$ \\
\hline Sex for drugs & $31 \quad(18.7 \%)$ & $19(18.6 \%)$ & 1.00 & $0.53-1.89$ & 0.93 & $0.48-1.81$ \\
\hline \multicolumn{7}{|l|}{ Drug use } \\
\hline Alcohol & $150 \quad(90.4 \%)$ & $94 \quad(92.2 \%)$ & 0.79 & $0.33-1.94$ & 0.86 & $0.35-2.14$ \\
\hline Marijuana & $69(41.6 \%)$ & $40 \quad(39.2 \%)$ & 1.10 & $0.67-1.82$ & 1.06 & $0.62-1.82$ \\
\hline Cocaine (intranasal) & $101(60.8 \%)$ & $64(62.7 \%)$ & 0.92 & $0.55-1.53$ & 0.96 & $0.55-1.68$ \\
\hline Cocaine (inject) & $16 \quad(9.6 \%)$ & $6 \quad(5.9 \%)$ & 1.71 & $0.65-4.51$ & 1.59 & $0.59-4.25$ \\
\hline
\end{tabular}

${ }^{a}$ OR: Odds ratio. ${ }^{b}$ AOR: Adjusted odds ratio, controlling for gender, age, race, education level, and income.

seventh-grade level of education; and $42.5 \%$ had an income lower than the average monthly income for residents of Rio de Janeiro (IBGE, 2003). No significant differences were found between the sociodemographic characteristics of these subjects and the characteristics of the overall population of patients seeking treatment in Centra-Rio/SES (Bastos et al., 2004).

Twenty-five (9.3\%) subjects reported difficulties in completing the ACASI interview due to problems in using the computer. The most frequent problem reported was "had problems understanding some questions". In the multivariate analyses, lower educational level (OR: 0.094; $95 \% \mathrm{CI}: 0.012,0.729$ ) was significantly associated with problems in using the computer.

Regarding perceptions of privacy with the two modes (ACASI vs. IAQ), more than one-third $(37.3 \% ; n=100)$ of the participants felt that their privacy was best protected by the ACASI mode, whereas $16.4 \%(n=44)$ answered that they preferred the IAQ mode, and $41 \%(n=111)$ felt there was no difference between modes. Similarly, almost half of the interviewees $(45.5 \% ; n=122)$ answered that the computer interview would produce more "honest" answers, compared with $30.6 \%(n=82)$ who reported that the IAQ was the best strategy to elicit honest answers and $16.8 \%$ $(n=45)$ who reported no differences between the modes.

In examining the potential impact of mode preference on participant reports of sexual risk behaviors and drug use, unadjusted and adjusted ORs were calculated. For these analyses, participants with a distinct preference for the IAQ mode were compared with all others. As displayed in Table 2, no significant associations were found in the frequency of reporting sexual risk behaviors or drug use.

Additional comments by participants included statements that the ACASI interview was "easy", "quick to answer", "made me feel more comfortable", "I could say things that I can't do with another person", and "a positive new experience". Other comments suggested including more questions on the assessment questionnaire. There were no negative comments about the use of computers.

\section{Discussion}

Our primary aim was to evaluate the acceptability of ACASI as a valid approach to assess risk among drug users entering treatment in Rio de Janeiro, Brazil. Furthermore, we wanted to address the question of whether preference for the ACASI had an impact on the reporting of risk behaviors. The importance of the findings is heightened by the fact that the data were collected in a cultural setting quite different from previous ACASI studies. The low rate of difficulties in using the ACASI among participants in this study suggests that this mode of interview is a feasible alternative to the IAQ when collecting data among drug users in Brazil and, potentially, other low- to middle-income countries. Not only did the study find that the ACASI approach is feasible, it also demonstrated good acceptability. The subjects endorsed the ability of ACASI to protect respondents' privacy and elicit honest responses. Perhaps most importantly, even though the subjects reported a slight preference for the IAQ in future interviews, the data suggest that this preference does not undermine the ability of the ACASI mode to elicit enhanced reporting of risk behaviors. In a companion paper, we present findings from a comparison of the two methods, showing that those subjects assigned to the ACASI reported significantly higher prevalence of risky drug and sexual practices than in the IAQ mode (Simões et al., 2006). Although the enhanced validity of the ACASI method is of primary concern, valid approaches that are not acceptable to the target population have limited utility. Thus, the data reported here have important implications for the future use of ACASI. Most of the problems that subjects reported in using the ACASI are easily adjusted with 
minimal programming modifications. The most frequently cited problem, "problems understanding some questions", is a critique of the wording of the questions and might reflect the fact that the interviewees were not familiar with some of the risk behaviors and drugs assessed by the questionnaire.

Although very few subjects overall reported difficulty in using the ACASI, this difficulty was associated only with respondents' educational levels. Van de Wijgert and colleagues (2000) previously reported the association between reported difficulties with ACASI and low educational level among study participants in Zimbabwe. In the Zimbabwe study, a respondent's low level of education was associated with problems using the keyboard, reading the screen, and correcting the answers. Increasingly, however, daily life requires people without special knowledge or training to use computers for daily activities, such as completing bank transactions, playing games, accessing public information services, or voting. Mills and colleagues (1996) describe "computer literacy" as a basic ability to recognize and interpret the visual language of computer technology, which does not require a sophisticated level of knowledge. This global trend toward more frequent interactions with computers and the concomitant efforts to simplify ACASI procedures might explain the low rate of problems encountered in this study and will continue to mitigate the role that respondents' educational levels play in the acceptability of the ACASI technology.

When asked about their acceptance of ACASI or choice of interview mode for future studies, a substantial number $(26.9 \%)$ of interviewees chose "no difference" or "I do not know". On the question regarding "privacy", almost half of respondents chose no preference at all. Metzger and colleagues (2000) found similar response rates when they administered the same questionnaire to gay men and injection drug users. The "no preference" answer might reflect acceptance of both methods. Again, it is important to note that we found no evidence that preference had an impact on reporting risk behaviors or drug use.

Considering the overall acceptance, the minimal technical problems encountered in using the computer, and the positive comments in the acceptability questionnaire, we were surprised by the number of participants who preferred to use the IAQ in future studies. Because the interviews were conducted in a drug-treatment facility but before the respondents had been evaluated for drug use and health issues, we suspect that the environment of a health care facility created expectations of personal contacts. Newman and colleagues (2002) suggest that because of the "impersonal nature of a computer interview", the face-to-face interview would be more appropriate for "questions related to psychological health issues".

It is important to consider the limitations of this study. The data were collected from drug users seeking treatment in a reference treatment center. Although the data reported are consistent with a growing body of ACASI research, the degree to which our findings can be generalized to drug users in the community and other settings in Brazil or elsewhere is limited.

Our study showed both good feasibility and acceptability of the ACASI risk assessment in a Brazilian health facility dedicated to the care and management of people facing problems with the use of alcohol and drugs. The ACASI technology appears to have advantages over the IAQ in eliciting data regarding sensitive behaviors and minimizing bias linked to the interviewer. The data reported here extend our understanding of the role of the ACASI method by suggesting the utility of this approach in assessing HIV risk among drug users in the context of a culturally diverse, lowto middle-income country.

\section{Acknowledgments}

This research was supported by grant 914/BRA/3014 from the Brazilian Ministry of Health - HIV/STD National Coordination and the Health Department of Rio de Janeiro State Government, with additional funds from the Center for Studies of Addiction at the University of Pennsylvania. We would like to acknowledge the following persons and institutions for their contributions to this research: ACORI staff - Lucia Beck, Claudete Bueno, Rosana Silva, Carlos Silva, Rita Barcelos, Nadima Bernacchi, Tereza Knett; São Francisco de Assis Hospital - Rosa Ferreira and Eliane Campagnuci; São Sebastião Institute - Eduardo Barbosa (in memoriam); Oswaldo Cruz Foundation - Mariana Hacker; the Centra-Rio/SES team; and the people who took part in the research.

\section{References}

Aquilino, W.S., 1997. Privacy effects on self-reported drug use: interactions with survey mode and respondent characteristics. In: Harrison, L., Huges, A. (Eds.), Validity of Self-Reported Drug Use: Improving the Accuracy of Survey Estimates. NIDA Res. Monogr. 167, 383-415.

Aquilino, W.S., Wright, D.L., Supple, A.J., 2000. Response effects due to bystander presence in CASI and paper-and-pencil surveys of drug use and alcohol use. Subst. Use Misuse 35(6-8), 845-867.

Bastos, F.I., Simões, A.M., Hacker, M., Malta, M., Metzger, D.S., 2004. Drug use patterns among new admissions to a substance treatment center in Rio de Janeiro, Brazil (poster). 65th Annual Scientific Meeting, College on Problem of Drug Dependence, and 2004 NIDA International Forum. Puerto Rico, USA.

Cooley, P.C., Rogers, S.M., Turner, C.F., Al-Tayyib, A.A., Willis, G., Ganapathi, L, 2001. Using touch screen audio-CASE to obtain data on sensitive topics. Comput. Human Behav. 17, 285-293.

Davis, L.J., Morse, R.M., 1991. Self-administered alcoholism screening test: a comparison of conventional versus computer-administered formats. Alcohol Clin. Exp. Res. 15(2), 155-157.

Des Jarlais, D.C., Paone, D., Milliken, J., Turner, C.F., Miller, H., Gribble, J., Shi, Q., Hagan, H., Friedman, S.R., 1999. Audio-computer interviewing to measure risk behaviour for HIV among injecting drug users: a quasirandomized trial. Lancet 353, 1657-1661.

Ellen, J.M., Gurvey, J.E., Pasch, L., Tschann, J., Nanda, J.P., Catania, J., 2002. A randomized comparison of A-CASI and phone interviews to assess STD/HIV-related risk behaviors. J. Adolesc. Health 31, 26-30.

Estado de São Paulo Newspaper, 2003. Dollar commercial-Historic. Available at http://www.estadao.com.br/ext/economia/financas/historico/ dolar_2000.htm. Accessed on April 27, 2005. 
Gribble, J.N., Miller, H.G., Cooley, P.C., Catania, J.A., Pollack, L., Turner, C.F., 2000. The impact of T-ACASI interviewing on reported drug use among men who have sex with men. Subs. Use Misuse 35(6-8), 869890.

Hewet, P.C., Erulkar, A.B., Mensch, B.S., 2004. The feasibility of computer-assisted survey interviewing in Africa. Experiences from two rural districts in Kenya. Soc. Sci. Comput. Rev. 2, 1-16.

IBGE, 2003. Demographic Census 2000 - Trabalho e Rendimento Resultados de amostra. Brazilian Institute of Geography and Statistics. Available at: ftp://ftp.ibge.gov.br/Censos/Censo_Demografico_2000/ trabalho_rendimento/Municipios/. Accessed on April 27, 2005.

Jennings, T.E., Lucenko, B.A., Malow, R.M., Dévieux, J.G., 2002. AudioCASI vs. interview method of administration of an HIV/STD risk of exposure screening instrument for teenagers. Int. J. STD AIDS 13, $781-784$.

Kissinger, P., Rice, J., Farley, T., Trim, S., Jewitt, K., Margavio, V., Martin, H.H., 1999. Application of computer-assisted interviews to sexual behavior research. Am. J. Epidemiol. 149(10), 950-954.

Locke, S.E., Kowaloff, H.B., Hoff, R.G., Safram, C., Popovsky, M.A., Cotton, D.J., Finkelstein, D.M., Page, P.L., Slack, W.V., 1992. Computerbased interview for screening blood donors for risk of HIV transmission. JAMA 268(10), 1301-1305.

LoSciuto, L., Aquilino, W.S., Licari, F.C., 1993. Interviewing minority youth about drug use: telephone vs. in-person surveys. In: De La Rosa, M.R., Adrados, J.R. (Eds.), Drug Abuse Among Minority Youth: Advances in Research and Methodology. NIDA Res. Monogr. 130, 201223.

Lucas, R.W., Mullin, P.J., Luna, C.B.X., Mcinroy, D.C., 1977. Psychiatrists and a computer as interrogators of patients with alcohol-related illnesses: a comparison. Br. J. Psychiatry 131, 160-167.

Mensch, B.S., Clark, W.H., Anh, D.N., 2003. Adolescents in Vietnam: looking beyond reproductive health. Stud. Fam. Plann. 34(4), $249-62$.

Metzger, D.S., Koblin, B., Turner, C., Navaline, H., Valenti, F., Holte, S., Gross, M., Sheon, A., Miller, H., Cooley, P., Seage, G.R., 2000. Randomized controlled trial of audio computer-assisted selfinterviewing: utility and acceptability in longitudinal studies. Am. J. Epidemiol. 152(2), 99-106.
Mills, A., Williams, M.L., Gordon, C., Young, P., Rusek, R., Signes, C.A., 1996. Reliability and Validity of an Audio-CASI Data Collection Instrument and Evaluation of Comparability with Face-to-Face Interviewing, Final Report to the National Institute on Drug Abuse (NIDA), June 1996. Community Research Branch, project NIH/NIDA 93-306.

Millstein, S.G., 1987. Acceptability and reliability of sensitive information collected via computer interview. Educ. Psychol. Meas. 47, 523-531.

Navaline, H.A., Snider, E.C., Petro, C.J., Tobin, D., Metzger, D.S., Alterman, A.I., Woody, G.E., 1994. Preparations for AIDS vaccine trials. An automated version of the Risk Assessment Battery (RAB): enhancing the assessment of risk behaviors. AIDS Res. Hum. Retroviruses 10(Suppl. 2), S281-283.

Newman, J.C., Des Jarlais, D.C., Turner, C.F., Gribble, J., Cooley, P., Paone, D., 2002. The differential effects of face-to-face and computer interview modes. Am. J. Public Health 92(2), 294-297.

Riley, E.D., Chaisson, R.E., Robnett, T.J., Vertefeuille, J., Strathdee, S.A., Vlahov, D., 2001. Use of audio computer-assisted self-interviews to assess tuberculosis-related risk behaviors. Am. J. Respir. Crit. Care Med. 164, 82-85.

Simões, A.M., Bastos, F.I., 2004. Audio computer-assisted interview: a new technology in the assessment of sexually transmitted diseases, HIV, and drug use. Cad Saude Publica 20(5), 1169-1181.

Simões, A.M., Bastos, F.I., Moreira, I.R., Lynch, K.G, Metzger, D.S., 2006. A randomized trial of audio computer-assisted self-interview (ACASI) and face-to-face to assess risk among drug and alcohol users entering treatment in Rio de Janeiro, Brazil. J. Subst. Abuse Treat., in press.

Turner, C.F., Ku, L., Rogers, S.M., Lindberg, L.D., Pleck, J.H., Sonenstein, F.L., 1998. Adolescent sexual behavior, drug use, and violence: increased reporting with computer survey technology. Science $280(5365), 867-$ 873.

Van de Wijgert, J., Padian, N., Shiboski, S., Turner, C., 2000. Is audio computer-assisted self-interviewing a feasible method of surveying in Zimbabwe? Int. J. Epidemiol., 29, 885-890. 